\title{
The onset of Arctic sea-ice snowmelt as detected with passive- and active-microwave remote sensing
}

\author{
Righard R. Forster, ${ }^{1}$ David G. Long, ${ }^{2}$ Kenneth C. Jezer, ${ }^{3}$ Sheldon D. Drobot, ${ }^{4}$ \\ Mark R. Anderson ${ }^{4}$ \\ ${ }^{1}$ Department of Geography, University of Utah, Salt Lake City, UT 84112, U.S.A. \\ ${ }^{2}$ Department of Electrical and Computer Engineering, Brigham Young University, Provo, UT 84602, U.S.A. \\ ${ }^{3}$ Byrd Polar Research Center, The Ohio State University, Columbus, OH 43210-1002, U.S.A. \\ ${ }^{4}$ Department of Geosciences, University of Nebraska, Lincoln, NE 68588, U.S.A.
}

\begin{abstract}
Daily acquisitions from satellite microwave sensors can be used to observe the spatial and temporal characteristics of the Arctic sea-ice snowmelt onset because the initial presence of liquid water in a dry snowpack causes a dramatic change in the activeand passive-microwave response. A daily sequence of backscatter coefficient images from the NASA scatterometer (NSCAT) clearly shows the spatially continuous progression of decreasing backscatter associated with snowmelt onset across the Arctic Ocean during spring 1997. A time series of the active NSCAT backscatter and a scattering index from the passive Special Sensor Microwave/Imager (SSM/I) show similar trends during the time of the melt onset. An NSCAT snowmelt-onset detection algorithm is developed using the derivative of the backscatter with respect to time to select a melt-onset date for each pixel, generating a melt map for the Arctic sea ice. Comparison between this melt map and one previously generated from an SSM/I scattering index shows the NSCAT algorithm predicts the onset occurs 1-10 days earlier than the SSM/I-based algorithm for most portions of multi-year ice.
\end{abstract}

\section{INTRODUCTION}

The onset of surface melt on Arctic sea ice plays an important role in the surface radiation budget by dramatically lowering the visible and near-infrared albedo, thereby increasing the amount of energy absorbed by the snow (Carsey, 1985). Yet little is known about the spatial characteristics and annual variability of melt onset and its connection to long-term changes in climate. Daily acquisitions from space-borne microwave remote-sensing instruments provide measurements at the appropriate time- and space scales. Unlike visible and near-infrared sensors which are not dependable because of cloud cover typical of spring conditions in the Arctic, microwave satellite-based sensors make measurements through cloud cover. Microwave sensors are also very sensitive to the presence of small amounts of liquid water in snowpack or on the sea-ice surface.

During the Arctic spring the melt begins at the surface and progresses downward with the movement of liquid water through open pore spaces (Marsh and Woo, 1984). Liquid water has a much higher relative permittivity at microwave frequencies than the constituents of dry snow (air and ice) (Ulaby and others, 1982). Therefore, at the transition of dry snow to wet snow (liquid water, ice and air) the relative permittivity increases dramatically, which increases the absorption and decreases volume scattering. This combination dramatically increases the emissivity, causing the wetsnow cover to act as a black body which results in an increased brightness temperature $\left(T_{\mathrm{B}}\right)$ recorded with passive-microwave sensors such as the Special Sensor Microwave/ Imager $(\mathrm{SSM} / \mathrm{I})$. Since the response of the active-microwave sensors (radars) to dry snow is dominated by volume scattering from within the snowpack itself and from below the snow surface, the increased absorption of wet snow near the surface strongly decreases the backscattered return (Ulaby and others, 1982). Because these effects take place at the top of the snowpack, the physics which cause the discernible changes in the electromagnetic response should be the same for first-year ice (FYI) and multi-year sea-ice (MYI) snow cover.

\section{Passive-microwave detection of snowmelt}

There have been numerous studies demonstrating the ability of space-borne passive-microwave sensors to detect the initiation of spring snowmelt on Arctic sea ice. Initial studies using the Electronically Scanning Microwave Radiometer (ESMR) (Campbell and others, 1984) were followed by applications using the Scanning Multichannel Microwave Radiometer (SMMR) (Anderson and others, 1985; Anderson, 1987; Serreze and others, 1993) and are continuing with the presently orbiting series of SSM/I (Garrity, 1992; Anderson, 1997; Smith, 1998). For a more detailed review of these works see Drobot and Anderson (in press).

A recent algorithm implemented on both SMMR and SSM/I data, spanning the years 1979-98, maps snowmelt-onset dates on the Arctic sea ice (Drobot and Anderson, in press). The algorithm is based on the difference in brightness temperatures $\left(T_{\mathrm{B}}\right)$ between the horizontally polarized 19 and $37 \mathrm{GHz}$ channels and referred to as the horizontal range (HR):

$$
\mathrm{HR}=T_{\mathrm{B}}(19 \mathrm{H})-T_{\mathrm{B}}(37 \mathrm{H}) .
$$

The HR value for sea ice with dry snow is typically positive, as the smaller wavelength of the $37 \mathrm{GHz}$ channel experiences 
more scattering from the overlying snow, decreasing its $T_{\mathrm{B}}$ relative to the $19 \mathrm{GHz}$ channel. However, with the presence of liquid water in the snowpack the emissivity and hence the $T_{\mathrm{B}}$ increases sharply with the shorter-wavelength $37 \mathrm{GHz}$ increasing more than the $19 \mathrm{GHz}$. Therefore, at the onset of snowmelt, HR decreases toward zero. Initially HR was used with a threshold of $2.0 \mathrm{~K}$ to predict melt onset over Arctic FYI and MYI (Anderson, 1997).

Recently the algorithm has been enhanced to take advantage of the time-series nature of the SMMR and SSM/I datasets (Drobot and Anderson, in press). The advanced horizontal-range algorithm (AHRA) first considers a day as a melt-onset event if the $\mathrm{HR}$ is $<4.0 \mathrm{~K}$. If $\mathrm{HR}$ is also less than $-10.0 \mathrm{~K}$ then the day is considered the melt-onset date. If the HR value is between 4.0 and $-10.0 \mathrm{~K}$ then the AHRA computes the range in HR values over the 10 days prior to the candidate onset day by subtracting the maximum and minimum $\mathrm{HR}$ values over these 10 day windows. In the same way the range in $\mathrm{HR}$ values over the period from the candidate day to 9 days later is computed. The range for the two time periods is compared. If the range after the potential melt day is $7.5 \mathrm{~K}$ greater than the range in $\mathrm{HR}$ over the 10 days prior to the candidate day then this day is assigned as the melt-onset date. The AHRA is implemented for each sea-ice pixel, producing a melt-onset map of the Arctic. Results of the AHRA using the SSM/I data for the 1997 melt onset are presented below for comparison with NASA scatterometer (NSCAT) observations of snowmelt onset.

\section{Active-microwave detection of snowmelt}

While active-microwave sensors are also sensitive to snowmelt, their use for mapping snowmelt onset of sea ice across the Arctic basin has not been investigated to the extent of the passive-microwave application. However, detailed studies combining space-borne SAR and in situ measurements on Arctic sea ice (at the Seasonal Sea Ice Monitoring and Modeling Site (SIMMS) in the Canadian Arctic Archipelago (LeDrew and Barber, 1994)) have shown that liquid water in the snowpack greatly reduces the backscatter (Barber and others, 1992) and this reduction is inversely correlated to surface temperature (Barber and others, 1994). A low-spatialresolution map (approximately $200 \mathrm{~km}$ pixels) of MYI meltonset dates for the Beaufort Sea was produced with European Remote-sensing Satellite 1 (ERS-1) synthetic aperture radar (SAR) scenes for 1992 (Winebrenner and others, 1994). The algorithm assigns a melt date to a location based on the linearly interpolated day when the mean value of an entire ERS-1 scene $(100 \mathrm{~km} \times 100 \mathrm{~km})$ initially drops below $-14 \mathrm{~dB}$. The more southerly area adjacent to the Alaskan coast, consisting of mainly FYI, was not included in the analysis because the contrast of pre-melt $\sigma^{\circ}$ (radar scattering coefficient) and melt-onset $\sigma^{\circ}$ was considerably lower than for MYI. This is a result of FYI having a lower pre-melt $\sigma^{\circ}$ than MYI.

Scatterometer data at Ku-band have been used to demonstrate its ability to infer the timing and extent of Arctic melt onset. Winebrenner and others (1998) and Drinkwater (1998) used Seasat scatterometer data. Long and Drinkwater (1999) showed the progression of melt onset across the North Slope of Alaska and the Beaufort Sea using a time series of NSCAT vertically polarized backscatter images. Each image uses 6 days of acquisitions, with the time series constructed from images centered every
3 days. (A resolution-enhancement technique is used that is explained in more detail in the following section.) The premelt backscatter for the FYI is considerably lower than for the MYI. The advance of melt on the MYI is clearly indicated by the progression of decreasing backscatter. The situation is more complex for FYI. It appears as though the backscatter initially increases before decreasing slightly as the melt moves from land across the FYI to the MYI.

Melt-onset dates for Antarctic sea ice have been estimated using both ERS-2 and NSCAT scatterometer data (Drinkwater and others, 1998). The datasets are based on 3 day images of the vertically polarized backscatter coefficient normalized to $40^{\circ}$ incidence angle with a pixel size of $8.8 \mathrm{~km}$. The images were smoothed with a twodimensional Gaussian filter with a half-width of approximately $56 \mathrm{~km}$. The algorithm for assigning melt dates uses the derivative of the backscatter with respect to time and requires that it be lower than $-0.5 \mathrm{~dB}$ for two consecutive days after the onset and that the total decrease be more than $-3 \mathrm{~dB}$ over at least 6 days.

While there has been work on both active and passive systems to detect melt onset over sea ice, there has yet to be an effort to compare the results of these sensors' response to snowmelt onset. Jin and Zhang (1999) compare the temporal variation of ERS-1 scatterometer with SSM/I brightness temperatures of the Greenland and Siberian snowpacks. They find that passive scattering indices $(19 \mathrm{~V}-37 \mathrm{~V}$ and $22 \mathrm{~V}-85 \mathrm{~V}$ ) are more sensitive to the temporal evolution of the snowpack and more correlated with the ERS backscatter than the individual brightness-temperature channels. This paper will compare the response of a passive and an active sensor to sea-ice melt onset. Corresponding algorithms for detection of melt onset are discussed. A new algorithm for the active scatterometer is presented, while the algorithm using the passive data has been previously developed and is discussed here for comparison.

\section{DATASETS}

The SSM/I is a seven-channel, four-frequency, linearly polarized (VVand $\mathrm{HH}$ ), passive-microwave radiometer which orbits on one of the Defense Meteorological Satellite Program (DMSP) satellites. It measures brightness temperatures at 19.35, 22.235, 37.0 and $85.5 \mathrm{GHz}$. This analysis will use daily observations of the $19 \mathrm{H}$ and $37 \mathrm{H}$ channels with a $25 \mathrm{~km}$ spatial resolution. These data, DMSP-F13 brightness temperatures, were obtained from the Earth Observation System Data and Information System (EOSDIS) National Snow and Ice Data Center Distributed Active Archive Center (NSIDC DAAG), University of Colorado at Boulder (NSIDC, 1999).

The NSCAToperated at Ku-band $(14 \mathrm{GHz})$ and flew on board the Japanese Advanced Earth Observation Satellite (ADEOS) from August 1996 to June 1997 (Naderi and others, 1991). It recorded radar backscatter measurements at vertical and horizontal polarizations at a range of incidence and azimuth angles with a nominal spatial resolution of $25 \mathrm{~km}$. The multiple observation each day, particularly in the polar regions, allowed the spatial resolution of the images to be improved to nearly $8 \mathrm{~km}$ using the scatterometer image reconstruction with filtering (SIRF) resolution-enhancement algorithm (Long and others, 1993). This multivariate algorithm is a non-linear resolution-enhancement technique based on modified 


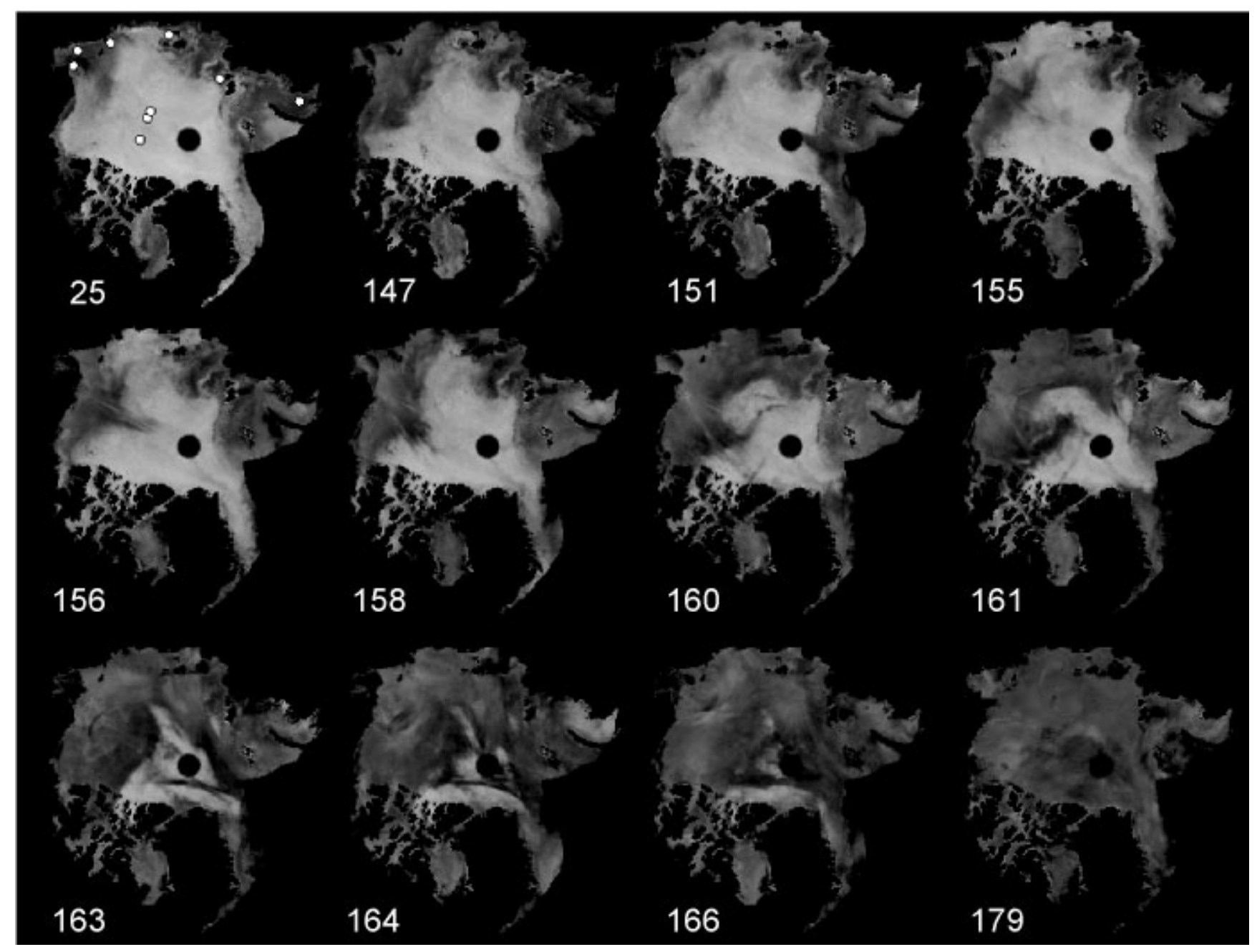

Fig. 1. A time series of daily NSCAT backscatter coefficient (normalized to $40^{\circ}$ incidence at vertical polarization) images during selected dynamic portions of spring 1997.

algebraic reconstruction and maximum entropy techniques and has recently been modified for NSCAT (Long and Drinkwater, 1999). The output product of the NSGAT resolution-enhancement technique used in this analysis is the backscatter normalized to an incidence angle of $40^{\circ}$. The resolution-enhancement data used in this study are 1 day images, a higher temporal resolution than the typical 3-6 day temporal resolution used in previous NSCAT analysis (e.g. Long and Drinkwater, 1999).

\section{SPATIAL PROGRESSION OF MELT}

A time series of daily NSCAT backscatter (at $40^{\circ} \mathrm{VV}$ ) images during selected dynamic portions of spring 1997 is shown in Figure 1. The NSCAT data have been averaged using a $5 \times 5$ window increasing the pixel size to $22.25 \mathrm{~km}$, similar to the $25 \mathrm{~km}$ pixels of the SSM/I. The land portions are removed and an ice mask has been applied. The first image is a typical winter scene showing pre-melt conditions (day 25). In general, the FYI has lower backscatter than the MYI, as it is smoother (at the cm-scale wavelength of NSCAT) and has less volume scatter from air bubbles (Onstott, 1992). From this first image to day 146, little change in backscatter occurs. However, by day 147 there is a significant reduction in backscatter in the Beaufort, Chukchi and East Siberian Seas. By day 151 the backscatter has returned to higher levels in most of these areas, but the Greenland Sea has become darker including a wedge extending from near Svalbard toward the pole. These decreases are temporary, as by day 155 the backscatter in the Greenland Sea increases and the wedge of low returns disappears.

The next 11 days of the spring show the greatest change in backscatter values of the entire 1997 time series. Between days 155 and 156 there is a narrow protrusion of low backscatter emanating from the Chukchi/Beaufort Sea boundary. It broadens and moves eastward through day 158 when another wedge of low backscatter shoots west, curling toward the pole on day 160. This wedge expands south, leaving a hook-shaped peninsula of high backscatter curling back toward the Bering Strait at day 161. During this time there is a poleward progression of decreasing backscatter in the Laptev, East Siberian and Greenland Seas. The remaining triangular region of high backscatter centered on the pole at day 163 is cut by a streak of low backscatter arching from Svalbard toward the Beaufort Sea just south of the pole. By day 166 there are only isolated areas of high backscatter remaining, with the largest off the north coast of Greenland and the Queen Elizabeth Islands. These areas gradually darken over the next several days, leaving the entire Arctic basin with low backscatter by the end of NSCATacquisitions on day 179 .

We interpret this sequence of decreasing backscatter to be the progression of snowmelt onset across the Arctic sea ice. The general homogeneity and large extent of the low-back- 

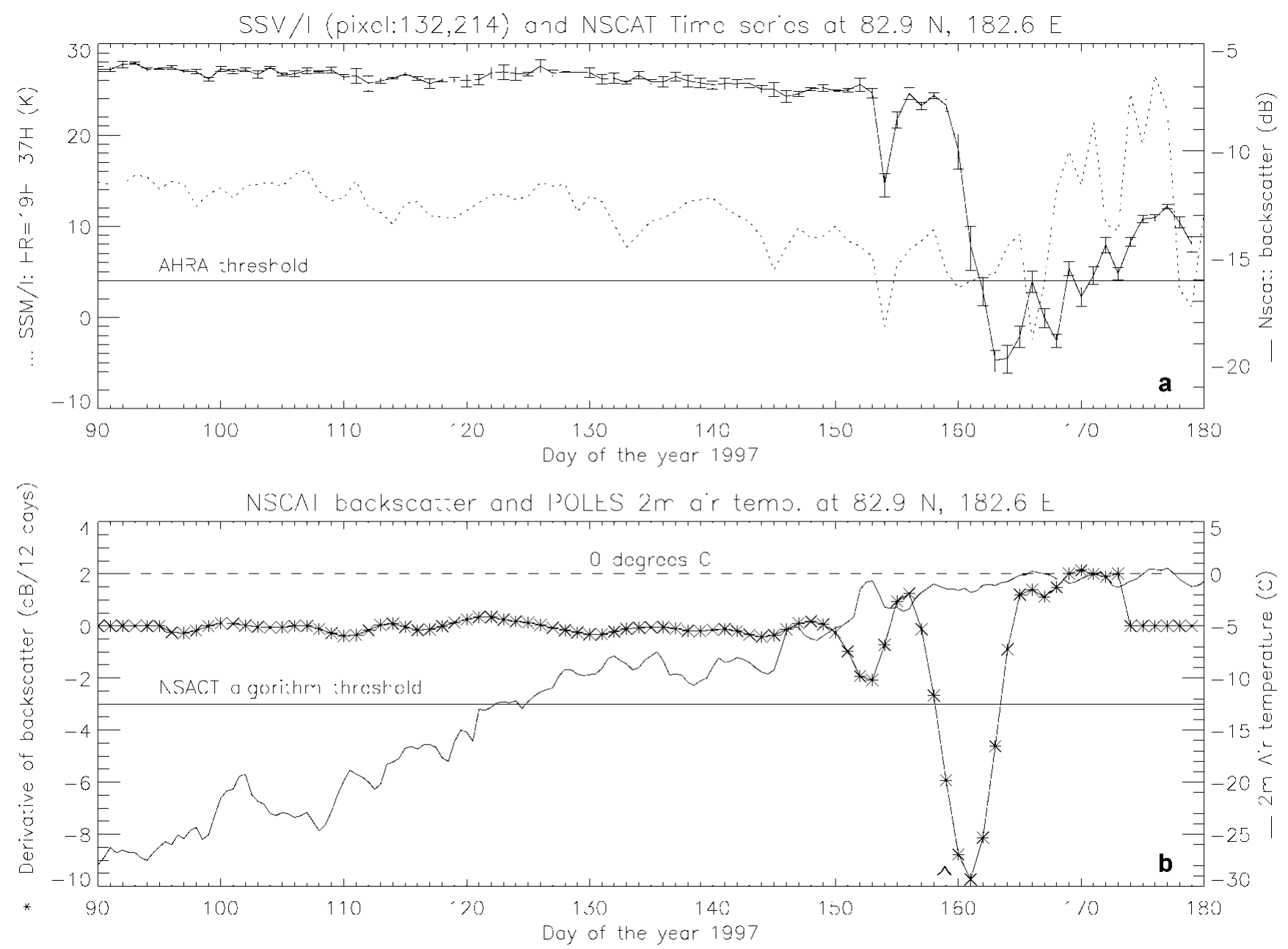

Fig. 2. A time series for MYI in the Arctic Ocean at $82.9^{\circ} \mathcal{N}, 177.4^{\circ} \mathrm{W}$. (a) The NSCAT points are the mean of $25 \times 25,4.45 \mathrm{~km}$ pixels centered on the location of the corresponding SSM/I pixel. The error bars represent \pm one standard deviation for the 625pixel area. The HR (Equation (1)) data are for a single $S S M / I 25 \mathrm{~km}$ pixel (dashed line). (b) The derivative of a Gaussian convolved with the backscatter is shown as the ** line. The full width of the Gaussian is 12 days with a threshold value of -3.0. Air temperature at $2 \mathrm{~m}$ is from the nearest POLES gridcell.

scatter areas implies that it is not related to smaller-scale processes such as lead formation. It appears to have a spatial pattern similar to a synoptic weather front moving through the area. Other studies (Crane and Anderson, 1994; Drobot and Anderson, 2001) document cases where synoptic conditions influence melt onset in a similar fashion. In order to map the snowmelt-onset dates using the NSCAT data, an algorithm was developed to assign dates for each pixel corresponding to this sharp drop in backscatter.

\section{NSGAT SNOWMELT-ONSET ALGORITHM}

In order to avoid the problem of large differences between the initial backscatter values of FYI and MYI (Fig. la), preventing a simple threshold approach from operating on both ice types (e.g. Winebrenner and others, 1994), an algorithm similar to Drinkwater's (1998) is used. The change in backscatter value over time is used as the basis for the NSCAT snowmelt-onset detection algorithm. Mathematically, this is the derivative of the backscatter with respect to time. It is desirable to remove short-term (1-2 day) decreases in backscatter from consideration for snowmelt onset, as they may be related to temporary melt episodes and not the persistent spring snowmelt event.
The detection of a sharp change, in this case a drop, in a one-dimensional time series in the presence of noise (shortterm drops in backscatter) is similar to the identification of an edge in a two-dimensional image. A typical imageprocessing edge-detection procedure convolves a derivative of a Gaussian with the image data (Kennedy and Basu, 1999). Joshi and others (1999) used a one-dimensional application of this approach for detecting snowmelt onset of the Greenland ice sheet from the $19 \mathrm{~V}$ time of SSM/I. The same approach is used here on the NSCAT backscatter time series.

The algorithm has two free parameters: the width of the Gaussian (number of points used in the averaging), and the threshold value of derivative used to indicate the smoothed backscatter has decreased quickly enough to be considered the melt-onset event. Since we have no direct observations of onset during 1997 and we wish to compare the NSCAT response to the $\mathrm{SSM} / \mathrm{I}$ response, the parameters were selected by comparing the two sensors' time series at locations where melt-onset observations were made during 1989-91 (Fig. la). These are the same locations used to select the threshold for the HR algorithm (Anderson, 1997) and make modifications to this algorithm producing the AHRA (Drobot and Anderson, in press). The width of the derivative of a Gaussian and the threshold value was interactively selected to optimize the agreement of the onset dates for the 
SSV/| (pixel:15<,160) and NSCAT Time seres at $72.9 \mathrm{~N}, 135.3 \mathrm{E}$
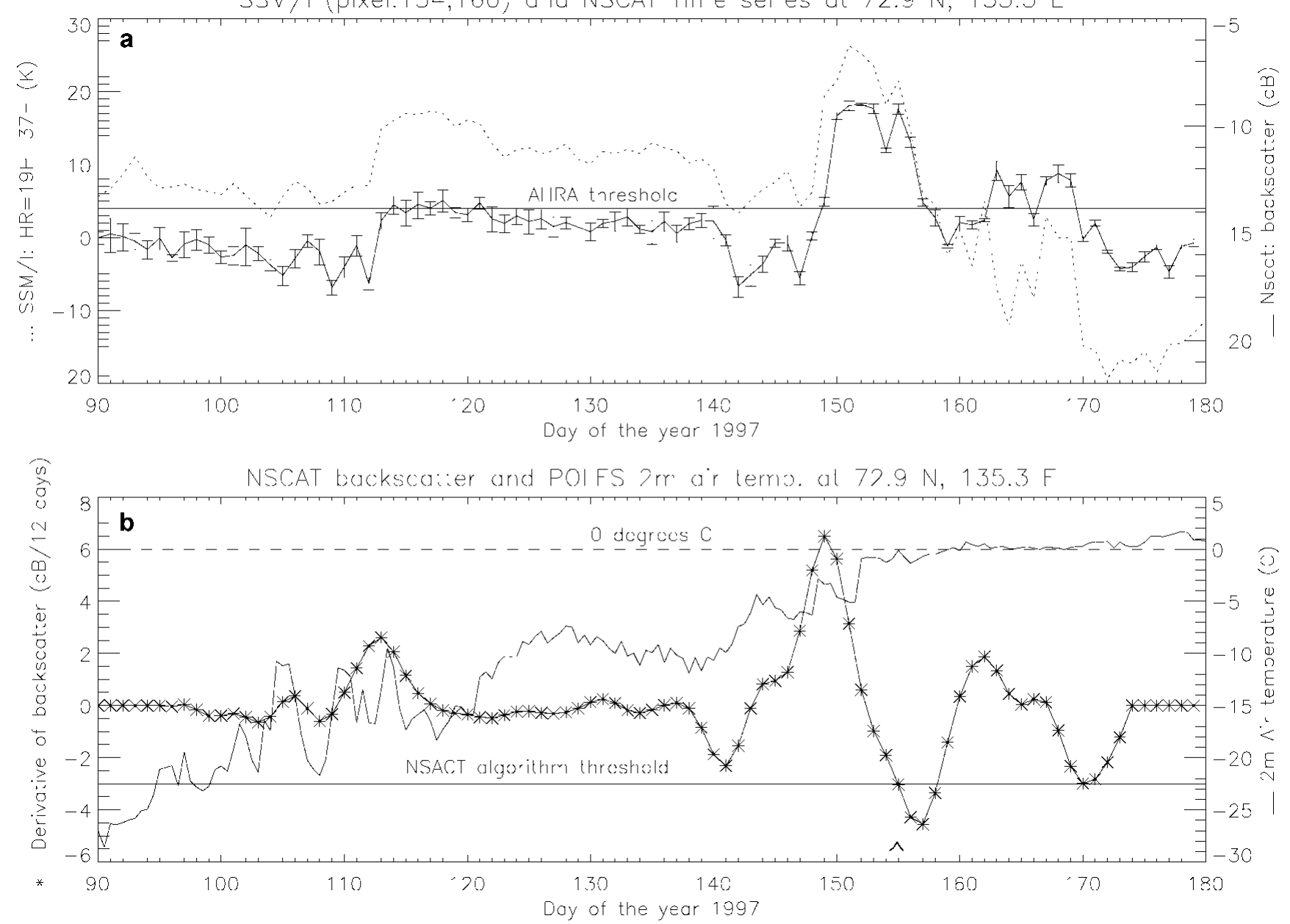

Fig. 3. A time series for FYI in the Laptev Sea at $72.9^{\circ} \mathcal{N}, 135.3^{\circ}$ E. The data types in (a) and (b) are the same as those shown in Figure 2 and explained in its caption.

AHRA and the NSCAT algorithms while also minimizing the number of pixels without a detected onset date.

Time series of NSCAT backscatter and SSM/I 19H-37H (HR) of snowmelt-onset observation points are used to constrain the NSCATalgorithm. Figure 2 is an example time series for MYI in the Arctic Ocean at $83^{\circ} \mathrm{N}, 177^{\circ} \mathrm{W}$. Surface air temperatures from the International Arctic Buoy Programme/Polar Exchange at the Sea Surface (IABP/ POLES) (Rigor and others, 2000) are shown as a proxy for snowmelt-onset observations. At day 154, HR crosses the $4 \mathrm{~K}$ threshold for the first time, but since the fluctuations are not greater by $>7.5 \mathrm{~K}$ after the threshold crossing than before, this day is not considered the onset date. The POLES data indicate that this corresponds with a temporary warming approaching $0^{\circ} \mathrm{C}$, followed by a sharp decrease in temperature. The AHRA continues to the next threshold crossing at day 160 where the pre- and post-crossing fluctuations are $>7.5 \mathrm{~K}$ and the day is assigned as the snowmelt-onset date. By this time the surface air temperature has returned to within a degree of zero. The NSCAT backscatter also has a single-day decrease at day 154 . After returning to previous levels for 4 days the backscatter decreases sharply, dropping $12 \mathrm{~dB}$ over the next 4 days. After day 165 the backscatter oscillates as it continues to increase over the last 2 weeks. Interestingly, the HR curve has a similar behavior over this time period. Both are probably responding to freeze/thaw cycles occurring after the initial snowmelt. This is supported by the POLES data oscillating around zero from day 165 to day 180. The derivative of a Gaussian convolved with the backscatter yields the dashed curve, and when combined with a threshold forms the NSCAT snowmelt-onset algorithm. The full width of the Gaussian is set to 12 days, and the threshold value of -3.0 selects an onset date of day 159. The smoothing effect of the Gaussian insures that the isolated decreases in backscatter at day 154 (associated with the temporary increase in temperature) followed by a continuation of high backscatter does not inappropriately trigger the NSCATalgorithm.

Figure 3 is an example time series for FYI in the Laptev Sea at $72^{\circ} \mathrm{N}, 137^{\circ} \mathrm{E}$. The initial pre-melt $\mathrm{HR}$ values are about $10 \mathrm{~K}$ lower than for the MYI example. (This is to be expected as the difference between the $37 \mathrm{~V}$ and $19 \mathrm{~V} \mathrm{GHz}$ channels is used as the numerator in the gradient ratio to discriminate between FYI and MYI in the NASA Team sea-ice classification algorithm (Cavalieri and others, 1984). However, this pre-melt difference is reduced since HR uses the horizontal channels rather than the vertical channels used by the gradient ratio.) The HR value dips below the AHRA threshold of $4 \mathrm{~K}$ at day 104 , but a similar variation on either side of this day keeps it from being assigned as melt onset with the temperature still less than $-10^{\circ} \mathrm{C}$. There is a sudden rise in $\mathrm{HR}(8 \mathrm{~K})$ between days 112 and 113 that gradually decreases over the next month. HR crosses the threshold once again at day 142 but without enough change in variability to signify snowmelt onset, consistent with an air temperature of $-7^{\circ} \mathrm{C}$. Another sharp increase in HR at day 149 is followed 5 days later by a 


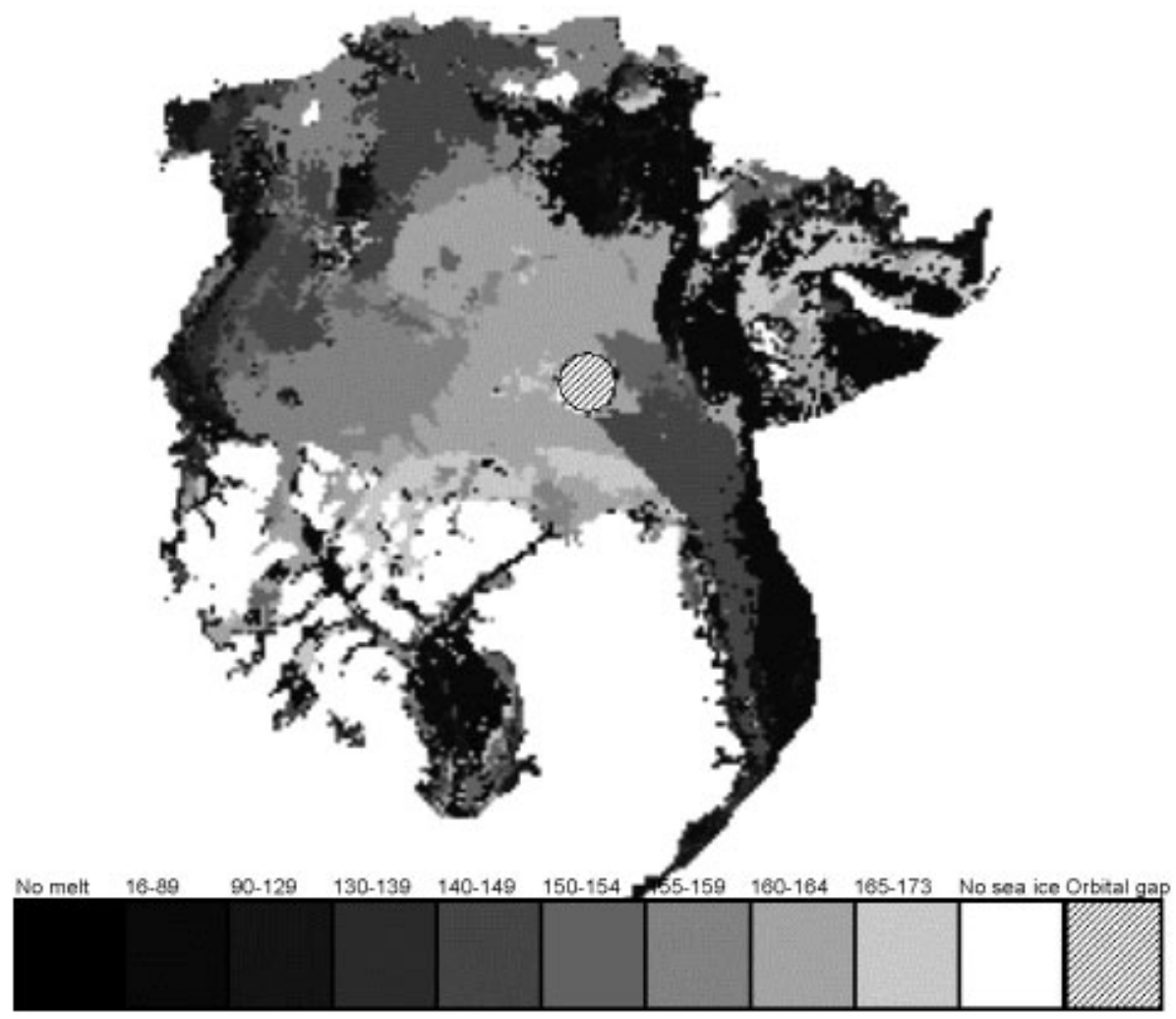

Fig. 4. A map of 1997 melt-onset dates derived from the NSCAT algorithm.

sudden decrease. While HR crosses the threshold at day 159, the AHRA conditions are not met until day 161 when the air temperature has risen above $0^{\circ} \mathrm{C}$.

The initial pre-melt NSCAT backscatter returns of the FYI example (Fig. 3) are $10 \mathrm{~dB}$ lower than the pre-melt returns for the MYI example (Fig. 2). The backscatter increases suddenly between days 112 and 113 just like the HR. The backscatter duplicates the changes in the HR through day 161, even including the short time-scale changes at days 146 and 156. The derivative of a Gaussian convolved with the backscatter emphasizes the two pre-melt sharp changes, but it is not until day 155 , when the temperature reaches $0^{\circ} \mathrm{C}$ for the first time, that the threshold is crossed and the NSCAT algorithm assigns snowmelt onset. After day 161 the two curves fluctuate, indicating a freeze/thaw process consistent with the temperatures oscillating around $0^{\circ} \mathrm{C}$, with the backscatter response showing less sensitivity than $\mathrm{HR}$.

Possible causes of the large pre-melt fluctuations for both sensors not present in the MYI examples are thought to be related to the advection of MYI into a portion of the pixel, changes in the snowpack (metamorphic grain growth (Barber and others, 1998) or new accumulation) or the wicking of brine upwards into the snowpack (Swift and others, 1992). The effect of lead formations and closures on both sensors is thought to be minimal because of the large pixel sizes used in this study (25.0 and $22.3 \mathrm{~km}$ ).

\section{MELT MAPS}

A melt-onset map for spring 1997 is produced by applying the NSCAT algorithm to reduced-spatial-resolution $(22.25 \mathrm{~km})$ daily NSCAT data (discussed in the section "Spatial progression of melt") acquired between days 16 and 179 (Fig. 4). Because of the 1 day temporal resolution of the dataset there are occasional areas of missing coverage on a particular day, but this is concentrated at the lower latitudes typically outside of the ice mask. This amounts to some pixels' time series missing one or two values over the 163 day sequence. These gaps are filled with a linear interpolation of the previous and next day's backscatter value.

The NSGATalgorithm melt map produced using a 12 day wide derivative of a Gaussian and threshold of $-3 \mathrm{~dB} \mathrm{~d}^{-1}$ is shown using a non-linear binning procedure (Fig. 4). The width of the bins is narrower around the days when most of the melt occurs, allowing the snowmelt progression's spatial pattern to be enhanced. The light-green areas represent pixels where the NSCAT algorithm did not detect any melt. These number $<2 \%$ of the pixels tested and are concentrated in areas of FYI in Baffin Bay, the Kara Sea and the Laptev Sea. In general, the algorithm predicts large areas of homogeneous melt-onset dates for the MYI. Most of the features on the melt map can be traced back to the episodes of decreasing backscatter seen in Figure 1. The areas assigned to days 140-149 in the Beaufort, Chukchi and East Siberian Seas are the result of the low backscatter seen at day 147 (Fig. 1b). The melt pattern from the Greenland Sea toward the pole is due to the decrease in backscatter between days 147 and 151 (Fig. $1 \mathrm{~b}$ and c). The progression of decreasing backscatter from day 155 to day 165 (Fig. ld-k), which encompasses most of the MYI, is clearly shown in two steps (days 155-159 and 160-164) on the melt map (Fig. 4). There are small areas of melt onset occurring between 165 and 173, most notably along the northern coasts of Greenland and Ellesmere Island, corresponding to the only remaining brightest areas on day 166 (Fig. 1k).

For comparison with passive-microwave data (SSM/I) and the AHRA, the 1997 melt-onset map (Drobot and Anderson, in press) is shown using the same non-linear bin widths used for the NSCAT algorithm melt map (Fig. 5). In 


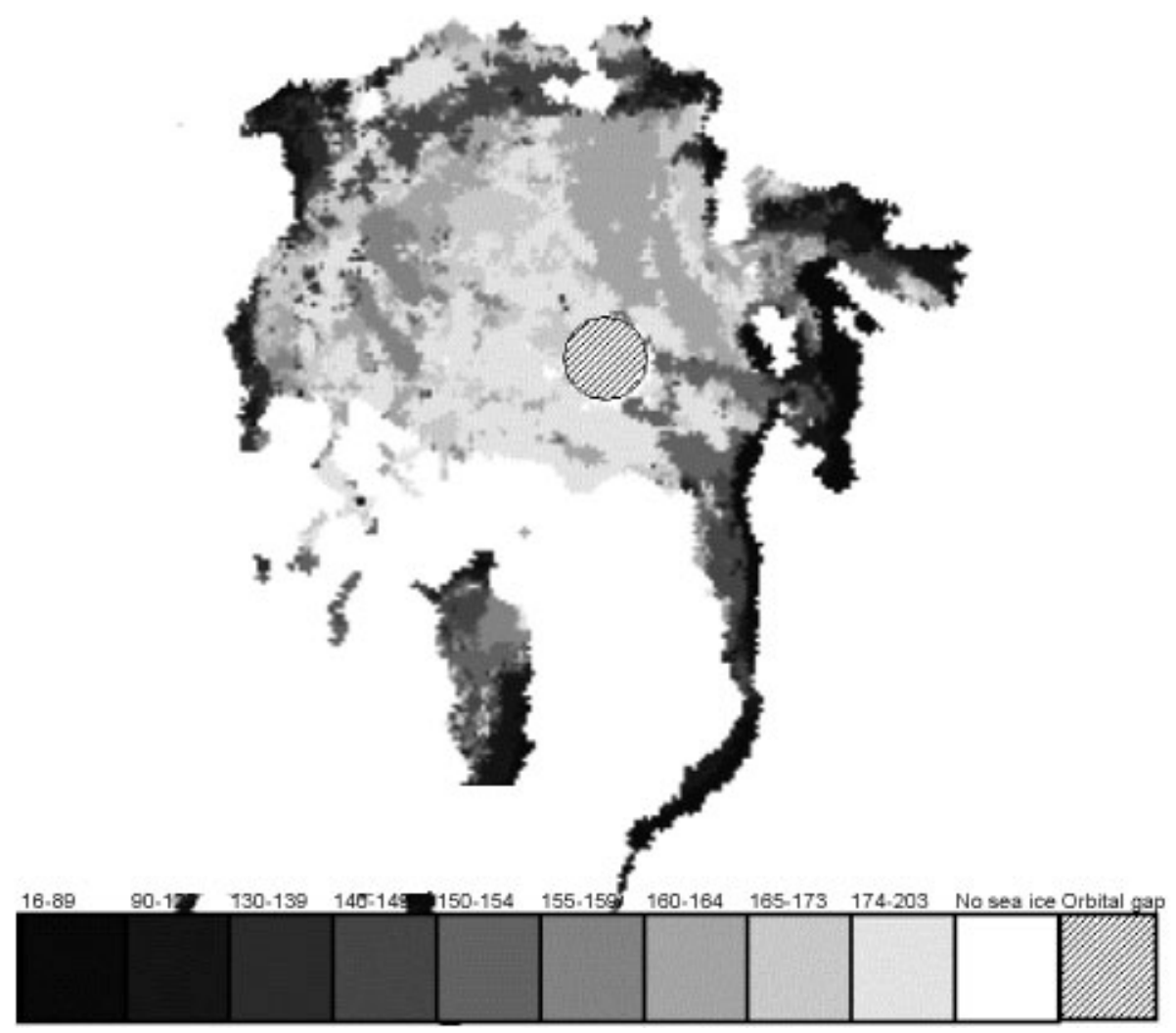

Fig. 5. A map of 1997 melt-onset dates derived from SSM/I data using the AHRA (Drobot and Anderson, in press).

general, the AHRA melt map shows the melt occurring later than the NSCATalgorithm. Over most of the MYI the difference is a shift of one 5 day wide bin. This implies the NSCAT algorithm is predicting the melt $1-10$ days earlier than the AHRA. In the eastern Arctic Ocean there is a region where both the AHRA and the NSCATalgorithm predict melt onset between days 160 and 164. There are smaller areas of MYI where they both predict the same range of onset dates, and a few isolated regions where the NSCATalgorithm is earlier by three or four 5 day bins. Comparison of the spatial pattern of the melt progression may be inhibited by the binning assignments chosen, but a comparison of the unbinned melt maps showed the same overall trends. In general, both melt maps show the earliest high-latitude melt occurring off the north coast of Svalbard extending toward the pole as two prongs of early melt. Because of the procedural differences in the two algorithms, care should be taken when comparing their resulting melt maps. Differences in the melt maps are the result of a combination of differences in the sensors' response to snowmelt onset and differences in the algorithms' approach to detection of this onset.

\section{DISGUSSION}

The NSCAT images clearly depict a dynamic decrease in backscatter during spring 1997 (Fig. 1). A sharp decrease in backscatter at $\mathrm{Ku}$-band is consistent with theoretical and observational examples of the onset of snowmelt. The spatial continuity and poleward progression of the pattern is additional evidence that this phenomenon represents the onset of Arctic sea-ice snowmelt. The NSCAT snowmelt-onset detection algorithm produces a melt-onset map (Fig. 1) consistent with the patterns seen in the image data, indicat- ing it is successfully capturing the movement of sharply decreasing backscatter. The relative progression of the onset dates seems reasonable, with the initial snowmelt occurring mostly on FYI, then generally progressing northward. The latest snowmelt-onset dates are on MYI off the northern coasts of Greenland and Ellesmere Island. The absolute timing of the snowmelt onset is also reasonable, occurring mostly between days 140 and 173 .

The current parameter settings of the NSCATalgorithm seem to limit its ability to detect onset for some areas of FYI. Baffin Bay and the Laptev Sea are areas where the pre-melt backscatter is very low (Fig. la) and consequently there is not a large enough decrease in backscatter over a short time period to indicate melt onset for the NSGATalgorithm. The Kara Sea is another area where onset was not detected. While it also has a very low winter backscatter it increases around day 158 (Fig. lf), then fluctuates before increasing again at day 164, then gradually decreases through day 179 . Since the NSCAT algorithm uses a derivative of a Gaussian with a 12 day full window it cannot assess the final 6 days of the time series for melt onset. Thus, if melt does not begin by day 173 it will not be detected by the NSCAT algorithm. Since the pixels immediately to the east of the Kara Sea "no-melt" pixels indicate the latest detectable melt dates, days $165-173$, it is possible that these "no-melt" pixels have not started to melt by day 173. Another problem with areas of FYI is the possible advection of MYI into the pixel. This dilemma is a consequence of monitoring temporal changes at a fixed location rather than over a fixed parcel of ice. This can be avoided by tracking individual ice parcels with NSCAT (Remund, and others, in press). However, the focus of this paper is to characterize the progression of melt as a function of geographic location and not to identify the melt onset for each ice parcel. 
The timing and pattern of the onset as seen in the image time series (Fig. 1) and the derived melt map (Fig. 4) indicate it is related to a synoptic-scale weather system. This implies a melt-onset map derived from these data for a given year may be more reflective of the spring weather conditions than of a climatic signal. However, an annual series of scatterometer melt maps could be used to observe the spatial dependency on decadal-scale climate signals in the same manner that the AHRA was used with the passivemicrowave dataset spanning 1979-98 (Drobot and Anderson, in press). Comparisons with the POLES data and the spatial homogeneity of the melt map over MYI lead us to believe the NSCAT snowmelt-onset algorithm can be used to detect potential climate change over decadal timescales for MYI regions. The algorithm is presently not reliable enough to be used for long-term studies on FYI.

While NSCAT is no longer in operation, its replacement, SeaWinds on board the QuikSCAT satellite, is presently in orbit and has been acquiring data since June 1999. This sensor, with similar characteristics to NSCAT, and its planned duplication on ADEOS-II will provide continuous $\mathrm{Ku}$-band scatterometer measurements for the next several years. Therefore, the NSCAT algorithm or a modification could be used to generate melt maps of the Arctic sea ice for the next decade. Since G-band has shown similar response to $\mathrm{Ku}$-band for detecting snowmelt onset of Antarctic sea ice (Drinkwater, 1998), it is reasonable to assume it will also respond to Arctic melt in the same manner. Therefore, an immediate application of the NSCAT algorithm to an 8 year time series is the ERS scatterometer operated at C-band from 1992 to the present.

The active NSCAT and passive SSM/I microwave sensors both respond to the initial presence of liquid water in a dry snowpack and therefore are useful tools for mapping Arctic sea-ice snowmelt onset. Time-series analysis of individual pixels has shown that the NSGAT backscatter and the SSM/I HR (Equation (1)) have similar fluctuation trends during the spring (Figs 2 and 3), while the HR has an apparently greater sensitivity in its response. There is a fundamental difference between these two parameters. The HR is a difference between two channels, while NSCAT backscatter is a single-channel measurement. An implication resulting from this difference is their response to FYI and MYI. The two-channel measurement decreases the dependency of HR on sea-ice type, allowing the AHRA to use an absolute threshold as part of its detection procedure. The NSCAT backscatter, conversely, is strongly influenced by sea-ice type, with FYI on the order of $10 \mathrm{~dB}$ lower than MYI. Therefore, the NSCAT algorithm must use a relative change in backscatter, computed as the derivative with respect to time, to signify melt onset.

The assumptions surrounding the timing of the decrease in signal indicating snowmelt are not the same for the two algorithms. The NSCATalgorithm assumes the backscatter decrease occurs fairly quickly. If the decrease in backscatter takes place gradually over an extended period of time it is possible for the NSCAT algorithm to miss the onset date and label the pixel as "no-melt". This scenario seems unlikely for most conditions since the presence of small amounts of liquid water in snow decreases the $\mathrm{Ku}$-band backscatter significantly. A slowly decreasing HR value approaching the melt threshold of the AHRA would not prevent the melt date from being detected as long as the fluctuations in HR after the threshold crossing are greater than the fluctuations before the threshold crossing (by $7.5 \mathrm{~K}$ ). Thus, the AHRA assumes there is a freeze/thaw cycle(s) within 10 days after the melt onset. AHRA has an additional provision that if $\mathrm{HR}$ falls below a lower threshold $(-10 \mathrm{~K})$ then melt onset is detected. This prevents pixels being assigned as "no-melt". The two algorithms also use different approaches for ignoring "negative spikes" (shortterm, sharp decreases) surrounded by a slowly varying signal (Fig. 2). These occurrences may be the result of a single-day melt followed by a return to prevailing cold conditions or atmospheric noise. The NSCAT algorithm filters these days with time-domain averaging coupled with the derivative. The AHRA requires an increased variability after the absolute threshold crossing.

A common limitation of these two active and passive datasets is the averaging of multiple acquisitions per day into a single daily response. This removes any diurnal signal caused, for example, by daytime melt and night-time refreezing. At snowmelt onset this is a typical scenario and could be used to indicate the initiation of melt. Alternative processing of the SSM/I data into separate ascending and descending observations (NSIDC, 2000) can indicate the presence of diurnal melt cycles (Ramage and others, 1999). The currently orbiting QuikSCAT's data are being processed into ascending and descending images which indicate daily thaw/freeze cycles.

\section{CONGLUSIONS}

Daily images of NSCAT backscatter (normalized VV at $40^{\circ}$ incidence) show a dramatic and spatially cohesive progression of decreased backscatter during spring 1997 on Arctic sea ice. We interpret this signal as the initiation of snowmelt on the ice. The spatial and temporal characteristics of this progression imply it is related to a synoptic-scale weather system. Daily time-series plots of NSCAT backscatter and SSM/I HR (Equation (1)) over about $25 \mathrm{~km}^{2}$ areas of FYI show similar trends that are in part related to surface melt. HR was more responsive than the backscatter after the melt onset, indicating it may be more responsive to melt/freeze cycling. The daily trends for the MYI time series are less similar. The NSCAT snowmelt-onset detection algorithm using a smoothed derivative of the NSCAT backscatter with a minimum threshold generates a melt-onset map that captures the spatial and temporal characteristics of the sharp decrease in backscatter. The melt map seems reasonable with respect to both the relative spatial progression and the absolute timing of the melt for most areas, with most of the MYI snowmelt onset occurring between days 155 and 164. The NSCAT algorithm has difficulty detecting a melt date for some FYI where the initial pre-melt backscatter is very low. A comparison of the NSCAT algorithm and the SSM/Ibased AHRA melt-onset algorithm shows the NSCAT algorithm estimates onset 1-10 days earlier in most locations. This is due to the combined differences in the response of the active and passive systems and the differences in the detection algorithms' assumptions of the speed of the melt and the presence of post-melt freeze/thaw cycles $(\mathrm{s})$. While NSCAT is no longer in operation and it has archived only one Arctic melt season, a snowmelt-onset detection algorithm similar to the NSCATalgorithm can be applied to the previous 8 years of ERS scatterometer data and the future dataset of the presently orbiting NSGAT replacement, Sea- 
Winds. Changes in the temporal and spatial progression of the snowmelt onset for MYI over multiple years, observed from an annual series of melt maps, can be investigated for indications of an earlier arrival of Arctic spring.

\section{ACKNOWLEDGEMENTS}

The authors would like to thank the two anonymous reviewers for their insightful comments and suggestions. This work was supported by NASA grant NAG5-8550. Brightnesstemperature data were obtained from the NSIDC.

\section{REFERENGES}

Anderson, M. R. 1987. The onset of spring melt in first-year ice regions of the Arctic as determined from scanning multichannel microwave radiometer data for 1979 and 1980. 7. Geophys. Res., 92(C12), 13,153-13,163.

Anderson, M. R. 1997. Determination of a melt-onset date for Arctic sea-ice regions using passive-microwave data. Ann. Glaciol., 25, 382-387.

Anderson, M. R., R. G. Crane and R. G. Barry. 1985. Characteristics of Arctic Ocean ice determined from SMMR data for 1979: case studies in the seasonal sea ice zone. Adv. Space Res., 5(6), 257-261.

Barber, D. G., E. F. LeDrew, D. G. Flett, M. E. Shokr and J. Falkingham. 1992. Seasonal and diurnal variations in SAR signatures of landfast sea ice. IEEE Trans. Geosci. Remote Sensing, GE-30(3), 638-642.

Barber, D. G., T. N. Papakyriakou and E. F. LeDrew. 1994. On the relationship between energy fluxes, dielectric properties, and microwave scattering over snow covered first-year sea ice during the spring transition period. 7. Geophys. Res., 99 (C11), 22,401-22,411.

Barber, D. G. and 7 others. 1998. The role of snow on microwave emission and scattering over first-year sea ice. IEEE Trans. Geosci. Remote Sensing, GE36(5), Part 2, 1750-1763.

Campbell, W. J., P. Gloersen and H. J. Zwally. 1984. Aspects of Arctic sea ice observable by sequential passive-microwave observations from the Nimbus5 satellite. In Dyer, I. and C. Chryssostomidis, eds. Arctic technology and policy. Washington, DC, Hemisphere Publishing Corp., 197-222.

Carsey, F. D. 1985. Summer Arctic sea ice character from satellite microwave data. 7. Geophys. Res., 90 (C3), 5015-5034.

Cavalieri, D. J., P. Gloersen and W. J. Campbell. 1984. Determination of sea ice parameters with the NIMBUS 7 SMMR. F. Geophys. Res., 89(D4), 5355-5369.

Crane, R. G. and M. R. Anderson. 1994. Springtime microwave emissivity changes in the southern Kara Sea. F. Geophys. Res., 99(C7), 14,303-14,309.

Drinkwater, M. R. 1998. Satellite microwave radar observations of Antarctic sea ice. In Tsatsoulis, C. and R. Kwok, eds. Analysis of SAR data of the polar oceans: recent advances. Berlin, etc., Springer-Verlag, 145-187.

Drinkwater, M. R., X. Liu, D. Low and P. Wadhams. 1998. Interannual variability in Weddell Sea ice from ERS wind scatterometer. In foint ESA-Eumestat Workshop on Emerging Scatterometer Applications: from Research to Operations. Proceedings. Noordwijk, Netherlands, European Space Agency. Publications Division, 119-123. (ESA SP-424.)

Drobot, S. D. and M. R. Anderson. 2001. Comparison of interannual snowmelt onset dates with atmospheric conditions. Ann. Glaciol., 33 (see paper in this volume).

Drobot, S. D. and M. R. Anderson. In press. Determination of snow melt onset over Arctic sea ice using passive microwave data. 7. Geophys. Res.

Garrity, K. 1992. Characterization of snow on floating ice and case studies of brightness temperature change during the onset of melt. In Carsey, F. D. and 7 others, eds. Microwave remote sensing of sea ice. Washington, DC, American Geophysical Union, 313-328. (Geophysical Monograph Series 68.)
Jin, Y. Q. and N. Zhang. 1999. Correlation of the ERS and SSM/I observations over snowpack and numerical simulation. Int. 7. Remote Sensing, 20(15-16), 3009-3018.

Joshi, M., J. F. Bolzan, K. G. Jezek and C. J. Merry. 1999. Estimation of the extent and duration of melt on the Greenland ice sheet using an edge detection technique on passive-microwave data. [Abstract.] EOS, 80 (17), Spring Meeting Supplement, S104-S105.

Kennedy, L. M. and M. Basu. 1999. A Gaussian derivative operator for authentic edge detection and accurate edge localization. Int. 7. Patt. Recogn. Artificial Intell., 13(3), 367-380.

LeDrew, E. F. and D. G. Barber. 1994. The SIMMS program: a study of change and variability within the marine cryosphere. Arctic, 47(3), 256-264.

Long, D. G. and M. R. Drinkwater. 1999. Cryosphere applications of NSCATdata. IEEE Trans. Geosci. Remote Sensing, GE-37(3), 1671-1684.

Long, D. G., P. J. Hardin and P.T. Whiting. 1993. Resolution enhancement of spaceborne scatterometer data. IEEE Trans. Geosci. Remote Sensing, GE-31 (3), 700-715.

Marsh, P. and M.-k. Woo. 1984. Wetting front advance and freezing of meltwater within a snow cover. 1. Observations in the Canadian Arctic. Water Resour. Res., 20(12), 1853-1864.

Naderi, F. M., M. H. Freilich and D. G. Long. 1991. Spaceborne radar measurement of wind velocity over the ocean - an overview of the NSCAT scatterometer system. Proc. IEEE, 79, 850-866.

National Snow and Ice Data Center (NSIDC). 1999. DMSP SSM/I brightness temperature grids for the polar regions, 1987-1999. Boulder, CO, University of Colorado. Cooperative Institute for Research in Environmental Sciences. National Snow and Ice Data Center.

National Snow and Ice Data Center (NSIDC). 2000. NOAA/NASA Pathfinder $S S M / I$ level 3 EASE-grid brightness temperatures. Boulder, CO, University of Colorado. Cooperative Institute for Research in Environmental Sciences. National Snow and Ice Data Center.

Onstott, R. 1992. SAR and scatterometer signatures of sea ice. In Carsey, F. D. and 7 others, eds. Microwave remote sensing of sea ice. Washington, DC, American Geophysical Union, 73-104. (Geophysical Monograph Series 68.)

Ramage, J. M., B. L. Isacks, C. M. Carter, K. H. Cook, M. M. Miller and A. C. Pinchak. 1999. SSM/I history of Alaskan glacier melt: the record and its relation to weather and climate in the last decade. [Abstract.] EOS, 80(46), Fall Meeting Supplement, F335.

Remund, Q. P., D. G. Long and M. R. Drinkwater. 2000. An iterative approach to multisensor sea ice classification. IEEE Trans. Geosci. Remote Sensing, 38(4), $1843-1856$.

Rigor, I., R. Colony and S. Martin. 2000. Variations in surface air temperature observations in the Arctic, 1979-1997. F. Climate, 13(5), 896-914.

Serreze, M. C., J. A. Maslanik, G. R. Scharfen, R. G. Barry and D. A. Robinson. 1993. Interannual variations in snow melt over Arctic sea ice and relationships to atmospheric forcing. Ann. Glaciol., 17, 327-331.

Smith, D. M. 1998. Observation of perennial Arctic sea ice melt and freeze-up using passive-microwave data. f. Geophys. Res., 103 (C12), 27,753-27,769.

Swift, C. T. and 7 others. 1992. Laboratory investigations of the electromagnetic properties of artificial sea ice. In Carsey, F. D. and 7 others, eds. Microwave remote sensing of sea ice. Washington, DC, American Geophysical Union, 177-200. (Geophysical Monograph Series 68.)

Ulaby, F. T., R. K. Moore and A. K. Fung. 1982. Microwave remote sensing, active and passive. Vol. 2. Radar remote sensing and surface scattering and emission theory. Reading, MA, Addison-Wesley Publishing Co.

Winebrenner, D. P., E. D. Nelson, R. Colony and R. D. West. 1994. Observation of melt onset on multiyear Arctic sea ice using the ERS 1 synthetic aperture radar. 7. Geophys. Res., 99 (C11), 22,425-22,441.

Winebrenner, D. P., D. G. Long and B. Holt. 1998. Mapping the progression of melt onset and freeze-up on Arctic sea ice using SAR and scatterometry. In Tsatsoulis, C. and R. Kwok, eds. Analysis of SAR data of the polar oceans: recent advances. Berlin, etc., Springer-Verlag, 129-144. 